\section{Regulation of vascular endothelial growth factor and pigment epithelium- derived factor in rat retinal explants under retinal acidification}

D Zhu' ${ }^{1,2}, X X u^{1}$, Z Zheng ${ }^{1}$ and $Q G^{1}$

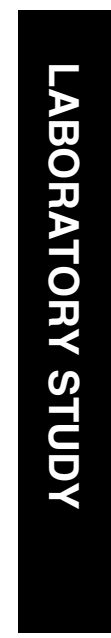

Introduction

The mammalian retina has an extraordinary high rate of aerobic glycolysis, that is the production of lactic acid, under the normal condition of oxygen and glucose availability. It must have the mechanisms of neutralizing or clearing the high production of $\mathrm{H}^{+}$to maintain the acid-base balance. In altered metabolic states (eg hypoxia, hyperglycemia), $\mathrm{H}^{+}$ accumulates because of the elevated glycolysis and failure of retinal circulation, thus the retina is readily acidified. ${ }^{1,2}$ Studies showed that retinal arterial occlusion or acute high intraocular pressure injury lead to retinal acidosis in cats or rabbits. ${ }^{3,4}$ Retinal acidification was also present in the conditions of hyperglycemia and diabetes in cats. ${ }^{5}$ Hypoxia and hyperglycemia are the most common states, which incur the retinal neovascularization. The exact mechanism is still unknown; however, the role of tissue acidosis has not been considered enough. In tumour pathogenesis, recently, a hypothesis of acid-mediated tumour invasion has been proposed, evidenced by the increased glucose uptake and tissue acidification in the tumours compared with normal tissue. The tissue acidosis resulting from elevated glycolysis promoted angiogenesis through the release of vascular endothelial growth factor (VEGF) and interleukin- $8 .{ }^{6}$ In addition, the preretinal neovascularization of neonatal rat, usually produced by exposure to constant hyperoxia followed by normoxia, thus caused relative hypoxia, was reported to be induced by making systemic acidosis alone ${ }^{7-9}$ which confirms the independent factor for acidosis in the development of angiogenesis. The
1Department of Ophthalmology, The First Affiliated Hospital, Shanghai Jiaotong University, Shanghai, China

${ }^{2}$ Department of Vitreous \& Retina, Ningbo Jiangdong Eye Hospital, Zhejiang, China

Correspondence: $\mathrm{XXu}$, Department of Ophthalmology, The First Affiliated Hospital, Shanghai Jiaotong University,

85, Wujin road, Shanghai 200080, China

Tel: + 8602163240090 ;

Fax: + 8602163240825

E-mail: xuxuneye@

163.com

Received: 18 February 2009 Accepted in revised form: 25 May 2009 Published online: 3 July 2009 
mechanism of induction of preretinal neovascularization by acidosis was related to VEGF. Acidic extracellular $\mathrm{pH}$ has been shown to induce VEGF transcription and expression in various types of tumour cells and endothelial cells. ${ }^{10-12}$ However, some found that decreased $\mathrm{pH}$ inhibited VEGF expression in rat C6 glioma cells, retinal Müller cells, ${ }^{13}$ and osteoblasts. ${ }^{14}$ The various $\mathrm{pH}$ levels and exposure times, and perhaps the different responses of various cells to $\mathrm{pH}$ alteration may make the difference. Pigment epithelium-derived factor (PEDF) is a potent angiogenic inhibitor. Until now, the relation of tissue acidosis to PEDF has not been studied. In this study, we used the retinal explants to investigate the effects of retinal acidification per se on the production of VEGF and PEDF. $\mathrm{pH}$ levels are not uniform throughout the normal retina. The lowest is in the proximal portion of outer retina ( $\mathrm{pH} 7.25)$, and it increases towards choroid ( $\mathrm{pH}$ 7.40) and vitreous ( $\mathrm{pH}$ 7.30). After dark adaptation, the lowest retinal $\mathrm{pH}$ may decrease to $7.15 .^{15}$ Thus, the acceptable $\mathrm{pH}$ for a healthy retina is considered to be about 7.2. Under the pathologic states, the lowest $\mathrm{pH}$ level retina can get is unknown. Owing to the embryological similarity between retina and cerebral cortex and the high aerobic glycolysis both tissues have, we used the moderate decrease of $\mathrm{pH} 6.5$ present in the ischemic brain as the lowest experimental $\mathrm{pH}$ in the experiment ${ }^{16}$ and $\mathrm{pH} 6.8$ as the median.

\section{Materials and methods}

\section{Retinal cultures}

\section{Acidic cultures}

All animal procedures were performed in accordance with the ARVO Statement for the Use of Animals in Ophthalmic and Vision Research.

Male Sprague-Dawley (SD) rats at postnatal day 14 were anesthetized and decapitated. The eyeballs were enucleated under sterile conditions and immersed in balanced salt solution on ice. The anterior segment and partial central vitreous body were removed and neural retinas were dissected. After introducing incisions in the shape of a Maltese cross to flatten out the retina tissues, the retina was transferred onto a Millicell-CM culture insert $(0.4 \mu \mathrm{m}, 30 \mathrm{~mm}$, Millipore, Bedford, MA, USA) with the photoreceptor side down. The insert was placed in a $35-\mathrm{mm}$ dish containing $1 \mathrm{ml}$ of culture medium. A small amount of mediums was added onto the retinas to keep them wet without covering them. The medium comprised of Dulbecco's modified Eagle medium (DMEM) with 2\% fetal bovine serum (Gibco BRL, Grand Island, NY, USA). For the experimental $\mathrm{pH}$, the concentration of bicarbonate in the DMEM base was adjusted to $22 \mathrm{mM}$ ( $\mathrm{pH} 7.2$ ), $9 \mathrm{mM}$ ( $\mathrm{pH} 6.8$ ), and $4 \mathrm{mM}$
(pH 6.5), respectively. Medium osmolarity was corrected by the addition of $\mathrm{NaCl}$. Cultures were maintained at $37^{\circ} \mathrm{C}, 95 \%$ air $/ 5 \% \mathrm{CO}_{2}$ for $24 \mathrm{~h}$. $\mathrm{pH}$ of the medium was measured using an ABL3 blood gas analyzer (Radiometer, Copenhagen, Denmark) and maintained within 0.05 of the targeted $\mathrm{pH}$ during the culture(data not shown).

\section{Acidic cultures followed by $\mathrm{pH}$ reversion}

To verify the modulation of VEGF and PEDF by retinal acidification, acidic cultures were followed by cultures with $\mathrm{pH}$ reversion back to the normal to observe the change of VEGF and PEDF. After $24 \mathrm{~h}$ of cultures with above different $\mathrm{pHs}$, each medium was removed and retinas were rinsed with PBS two times; fresh $\mathrm{pH} 7.2$ culture medium was added to each dish and cultures were continued for $24 \mathrm{~h}$.

Acidic culture with antioxidants

To study the role of oxidative stress in the regulation of VEGF and PEDF mediated by retinal acidification, retinas were incubated in the mediums with above $\mathrm{pHs}$ with antioxidants consisting of $\mathrm{N}$-acetyl-L-cysteine $(5 \mathrm{mM})$, catalase $(250 \mathrm{U} / \mathrm{ml})$, and superoxide dismutase $(100 \mathrm{U} / \mathrm{ml})$ for $24 \mathrm{~h}$. $\mathrm{pH}$ levels and osmolarity were corrected as described above.

\section{Histology}

To study the morphological changes of retinas caused by the organ culture, at $24 \mathrm{~h}$ after acidic culture, retinas were cut off together with membranes and fixed for $30 \mathrm{~min}$ by immersion in $4 \%$ paraformaldehyde, and then sandwiched between fresh liver tissues and fixation for $2 \mathrm{~h}$. After being dehydrated with graded ethanols and embedded in paraffin, retinas were sectioned and collected on glass slides, stained with hematoxylin and eosin, and then observed by microscopy.

\section{Quantitative real-time RT-PCR}

Before culture and after acidic culture, acidic culture followed by $\mathrm{pH}$ reversion and acidic culture with antioxidants, respectively, retinas were processed for quantitative real-time reverse transcription-ploymerase chain reaction (RT-PCR). The total RNA was isolated from retinal tissues using Trizol reagent. Primers for VEGF, PEDF, and $\beta$-actin were designed (Primer Express Software; Applied Biosystems, Foster City, California, USA) as follows: 5'CAGCTATTGCCGTCCAATTGA3 '(forward), 5'CCAGGGCTTCATCATTGCA3'(reverse) for VEGF; 5'ACAGGGCAGCTTTTGAGTGG3'(forward), 5'ATGAACGGTCGGTTAAGGTGATA3' (reverse) for PEDF; 5'CCTCTATGCCAACACAGTGC3'(forward), 
5'GTACTCCTGCTTGCTGATCC $3^{\prime}$ (reverse) for $\beta$-actin. VEGF primers were designed to identify all the isoforms of VEGF mRNA. RT reaction used $3 \mu \mathrm{g}$ total RNA, $0.5 \mu \mathrm{g}$ oligo-dT primer, and $1 \mu \mathrm{l}$ MMLV reverse transcriptase in a final volume of $20 \mu \mathrm{l}$ and was conducted at $37^{\circ} \mathrm{C}$ for $60 \mathrm{~min}$, followed by a denaturation at $95^{\circ} \mathrm{C}$ for $5 \mathrm{~min}$. The real-time PCR used $1 \mu \mathrm{l}$ of the RT product and $0.5 \mu \mathrm{M}$ of primers and was performed using a GeneAmp RNA PCR kit and SYBR Green PCR Master Mix (Applied Biosystems). The PCR mix was denatured at $95^{\circ} \mathrm{C}$ for $5 \mathrm{~min}$, followed by 35 cycles of denaturation at $95^{\circ} \mathrm{C}$ for $10 \mathrm{~s}$, annealing at $57^{\circ} \mathrm{C}$ for $15 \mathrm{~s}$, and extension at $72^{\circ} \mathrm{C}$ for 20 s. Fluorescence changes were monitored after each cycle. The relative cDNA concentrations were determined by a standard curve using sequential dilutions of the PCR fragments. The VEGF and PEDF mRNA levels were normalized by $\beta$-actin mRNA levels.

\section{Western blot analysis}

Retinas after acidic culture, acidic culture followed by $\mathrm{pH}$ reversion and acidic culture with antioxidants, respectively, were processed for western blot. The retinas were homogenized in a lysis buffer and centrifuged at $4^{\circ} \mathrm{C}$ for $10 \mathrm{~min}$. Protein concentration was measured with the BCA assay (Pierce Chemical Co., Rockford, IL, USA) according to the manufacturer's instructions. Then, $50 \mu \mathrm{g}$ of total protein was resolved by $15 \%$ SDS-PAGE under reducing conditions and electro-transferred onto a polyvinylidene difluoride membrane (BioRad, Hercules, CA, USA). After nonspecific binding was blocked with $5 \%$ normal goat serum, the membranes were blotted with a mouse monoclonal antibody against VEGF $(1: 1000$; Abcam, Cambridge, MA, USA) or PEDF (1:1000; Chemicon, Temecula, CA, USA) overnight at $4{ }^{\circ} \mathrm{C}$, followed by incubation with a secondary antibody for $2 \mathrm{~h}$ at room temperature. The anti-VEGF antibody detects the 121,165 , and 189 amino-acid isoforms of VEGF and shows 28, 31, $50 \mathrm{kDa}$ bands in western blot. The antiPEDF antibody specifies the $46 \mathrm{kDa}$ band.

Chemiluminescence reagents (ECL, Amersham, Piscataway, NJ, USA) were used to visualize the labelled protein bands according to the manufacturer's instructions. The same membrane was stripped and reblotted with an anti- $\beta$-actin antibody $(1: 500$; Santa Cruz Biotechnology, Santa Cruz, CA, USA) as normalization.

\section{ELISA}

After $24 \mathrm{~h}$ of acidic culture, VEGF protein concentration in the culture mediums was assayed by a VEGF sandwich ELISA kit (R\&D system Inc., Minneapolis, MN, USA) in triplicate according to the manufacturer's instructions. Values were normalized to total protein in the mediums. PEDF ELISAs were not performed because the levels of the protein in the culture mediums were below the detection levels of available assays.

\section{Statistical analysis}

Statistical analysis used the one-way ANOVA. Statistical difference was considered significant at a $P$-value $<0.05$.

\section{Results}

\section{Histology}

At day 15 after birth, the rat retinas had basically differentiated morphology. After $24 \mathrm{~h}$ of organ culture with air-medium interface, the architecture of retinas in the medium with $\mathrm{pH} 7.2$ or 6.8 appeared normal; however, that with $\mathrm{pH} 6.5$ showed apparent swelling and vacuolation of some cells in the inner nuclear layer (Figure 1).

\section{VEGF and PEDF levels after acidic culture}

At $24 \mathrm{~h}$ after acidic culture, VEGF and PEDF mRNA in the retinas of $\mathrm{pH} 7.2$ were not different than the intact retinas. VEGF mRNA levels were significantly increased in the retinas of $\mathrm{pH} 6.8$ and 6.5 compared with that of $\mathrm{pH}$ 7.2. $\mathrm{pH} 6.5$ was more intensive in the induction than $\mathrm{pH}$ 6.8 (Figure 2a); PEDF mRNA was significantly increased in the retinas of $\mathrm{pH} 6.5$ compared with that of $\mathrm{pH} 7.2$ (Figure 2b). Some of 28 and $50 \mathrm{kDa}$ bands of VEGF protein were missing in the western blot. VEGF 164 (31 kDa) (Figure 2c and d) and PEDF (Figure 2e and f) protein were increased in the retinas of $\mathrm{pH} 6.8$ or 6.5 compared with those of $\mathrm{pH}$ 7.2. With ELISA, VEGF protein concentrations in the culture mediums of $\mathrm{pH} 6.8$ $(16.93 \pm 1.89 \mathrm{pg} / \mathrm{mg}, P<0.05)$ and $\mathrm{pH} 6.5$ $(21.33 \pm 1.67 \mathrm{pg} / \mathrm{mg}, P<0.01)$ were higher than that of $\mathrm{pH} 7.2(12.0 \pm 1.59 \mathrm{pg} / \mathrm{mg})$.

\section{VEGF and PEDF levels after acidic cultures followed by $p H$ reversion}

When acidic mediums were returned to normal $\mathrm{pH}$, the increased VEGF (Figure 3a) and PEDF (Figure 3b) mRNA levels recovered and the increased VEGF (Figure 3c) and PEDF (Figure 3d) protein reduced.

\section{Effects of antioxidants on VEGF and PEDF levels under acidic culture}

Antioxidants completely inhibited the increased VEGF mRNA in the retinas of $\mathrm{pH} 6.8$. At $\mathrm{pH} 6.5$, although the 

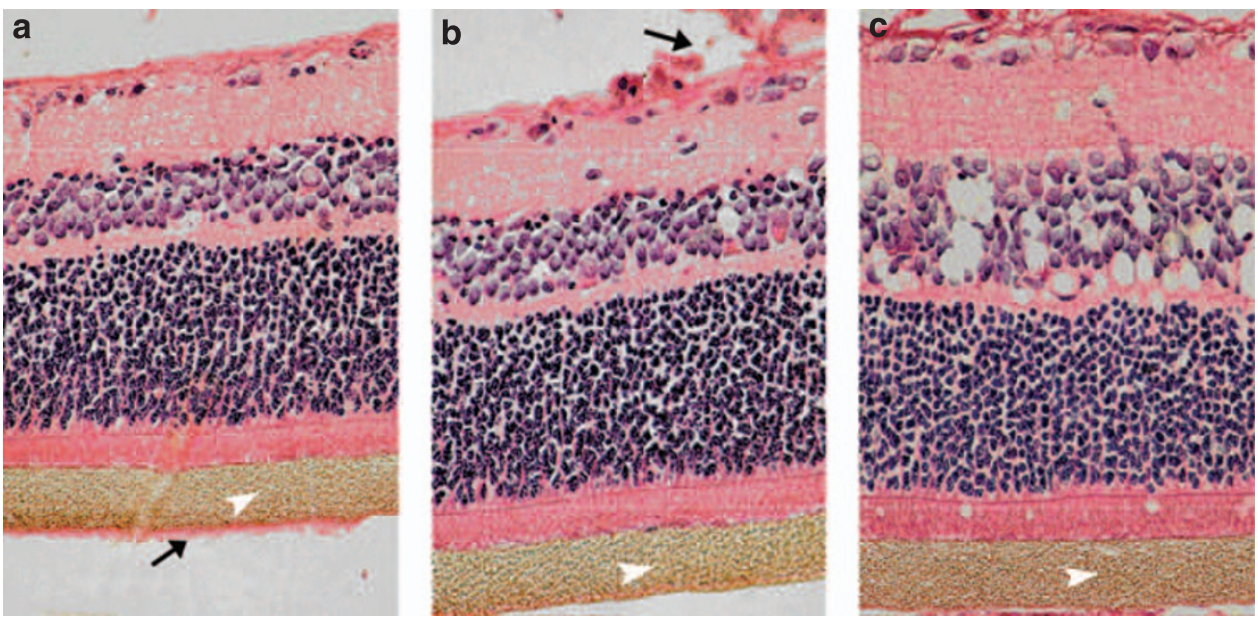

Figure 1 Photomicrographs of rat retinal explants after $24 \mathrm{~h}$ of culture under various $\mathrm{pH}$ levels. Retina together with membrane (arrowhead) was sandwiched between liver tissues (arrow) and cut with a radial section. The architecture of the retina of $\mathrm{pH} 7.2$ (a) or pH 6.8 (b) exhibits normal layers. However, in the retina of pH 6.5, swelling and vacuolation of some cells are visible in the inner nuclear layer (INL) (c). (H\&E, original magnification, $\times 400)$.

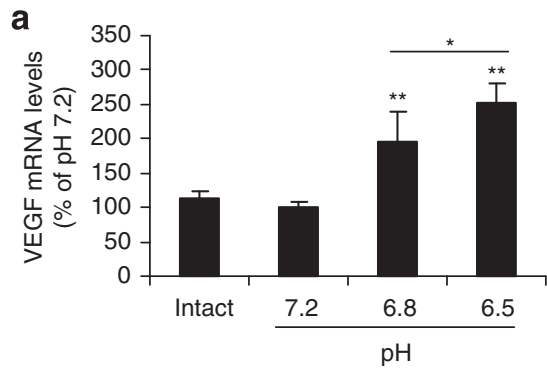

b

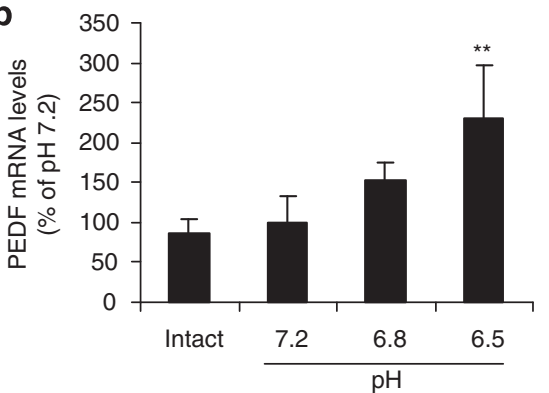

C kD

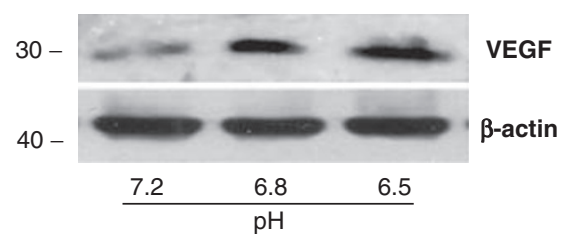

d

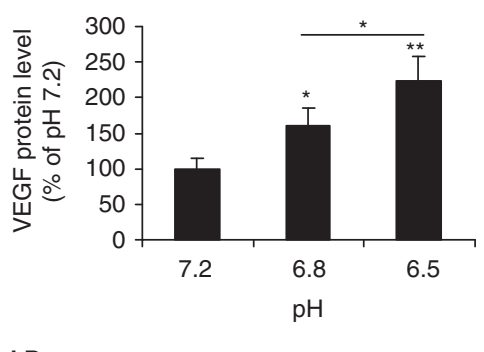

e $\mathrm{kD}$

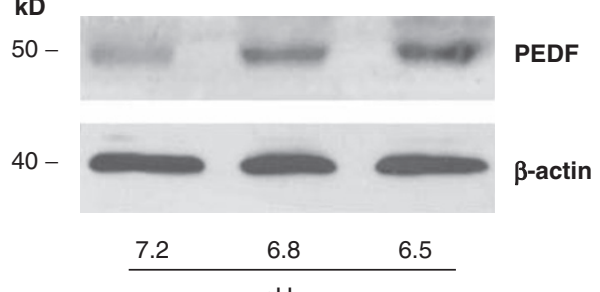

$\mathrm{pH}$

$\mathbf{f}$

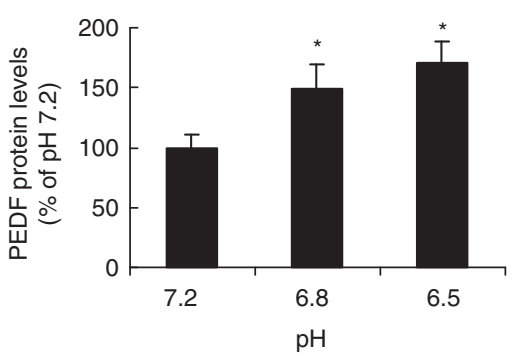

Figure 2 Retinal VEGF and PEDF levels changes under acidic culture. VEGF (a) and PEDF (b) mRNA levels at the time before and $24 \mathrm{~h}$ after organ culture of retinas in the mediums with $\mathrm{pH} 7.2,6.8$, and 6.5 , respectively, were determined by real-time RT-PCR and normalized by $\beta$-actin mRNA levels. The average mRNA level was expressed as a percentage of $\mathrm{pH} 7.2(\mathrm{means} \pm \mathrm{SD}, n=4)$; Western blot analysis of VEGF(c and d) and PEDF (e and f) protein at $24 \mathrm{~h}$ after organ culture of retinas in the mediums with $\mathrm{pH} 7.2,6.8$, and 6.5 , respectively, was normalized by the $\beta$-actin protein levels, and expressed as a percentage of $\mathrm{pH} 7.2(\mathrm{means} \pm \mathrm{SD}, n=3$ ). Representative blots (c and e) and quantification analysis ( $\mathrm{d}$ and $\mathrm{f}$ ) are shown. Values statistically different from pH 7.2 and between $\mathrm{pH} 6.8$ and 6.5 are indicated by ${ }^{*} P<0.05,{ }^{* *} P<0.01$. 

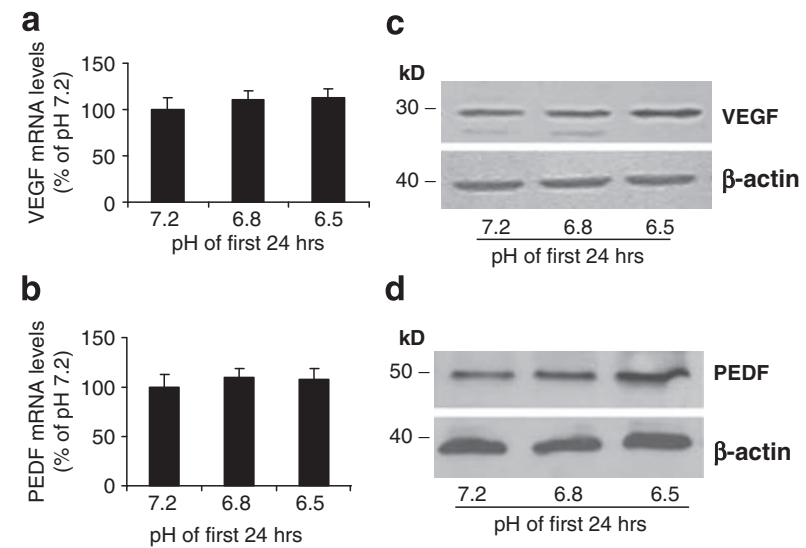

d

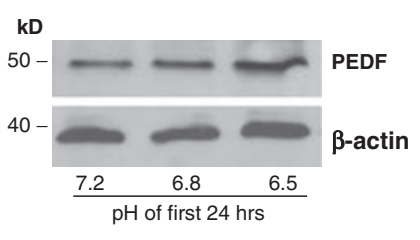

Figure 3 Retinal VEGF and PEDF levels changes after acidic culture followed by $\mathrm{pH}$ reversion. After $24 \mathrm{~h}$ of culture in the mediums with $\mathrm{pH} 7.2,6.8$, and 6.5, respectively, fresh $\mathrm{pH} 7.2$ medium was substituted for each medium and cultures were continued for $24 \mathrm{~h}$. VEGF (a) and PEDF (b) mRNA levels were determined by real-time RT-PCR and normalized by $\beta$-actin mRNA levels. The average mRNA level was expressed as a percentage of $\mathrm{pH} 7.2$ (means $\pm \mathrm{SD}, n=3$ ). Western blot analysis of VEGF (c) and PEDF (d) protein was normalized by the $\beta$-actin protein levels. Representative blots are shown. There was no difference between each group.

induction of VEGF mRNA was largely reduced, it was still significantly higher than that at pH 7.2 (Figure 4a). Antioxidants had not prevented the increased PEDF mRNA; on the contrary, further increased PEDF mRNA (Figure 4b). Antioxidants completely inhibited the increased VEGF protein in the retinas of $\mathrm{pH} 6.8$, and reduced it in the retinas of $\mathrm{pH} 6.5$, consistent with their mRNA (Figure 4c). PEDF protein was increased in acidic retinas by antioxidants (Figure $4 \mathrm{~d}$ ).

\section{Discussion}

Multiple retinal cell types make VEGF, including ganglion, Müller, and retinal pigment epithelium cells. Since the retinal pigment epithelia are nourished by the rich choroidal circulation, they are seldom impaired by hypoxia and acidosis, thus their role in the production of VEGF was ruled out in the present experiment. ${ }^{17}$

Although study reported decreased VEGF protein secreted by retinal Müller cells in the culture medium with low $\mathrm{pH}$ (7.0) compared with that with normal $\mathrm{pH}$ $(7.4),{ }^{13}$ we found that the production of VEGF mRNA and protein was elevated in the retinal explants by organ culture under acidic conditions. The organ culture of neonatal retina, in contrast to culture of dissociated retinal cells, has the advantage of retaining cell-cell contacts and interactions among different cell populations, and has become an ideal choice for in vitro studies on biochemical and metabolic alterations. It is

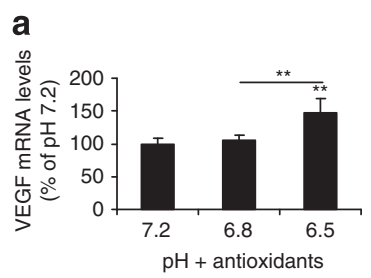

c
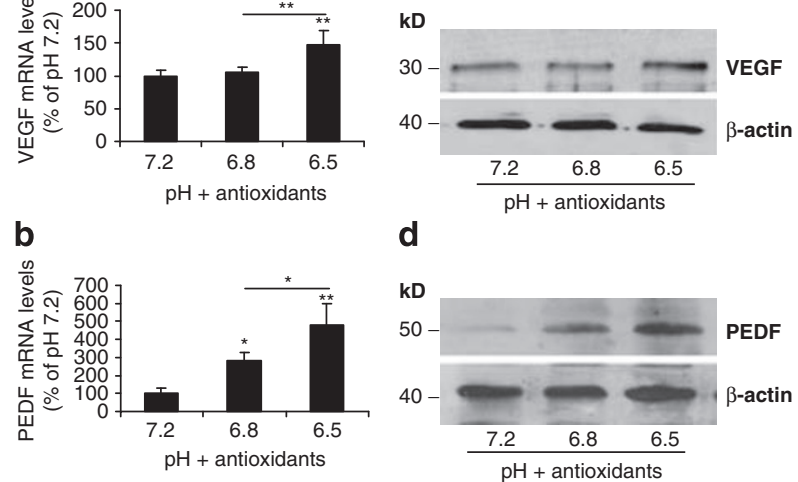

d

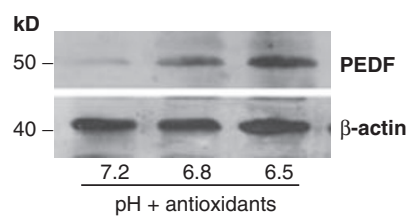

Figure 4 Retinal VEGF and PEDF levels changes under acidic culture with antioxidants. Retinal explants were incubated in the mediums with antioxidants consisting of $\mathrm{N}$-acetyl-L-cysteine, catalase, and superoxide dismutase at $\mathrm{pH} 7.2,6.8$, and 6.5, respectively, for $24 \mathrm{~h}$. VEGF (a) and PEDF (b) mRNA levels were determined by real-time RT-PCR and normalized by $\beta$-actin mRNA levels. The average mRNA level was expressed as a percentage of $\mathrm{pH} 7.2$ (means $\pm \mathrm{SD}, n=4$ ). Values statistically different from $\mathrm{pH} 7.2$ and between $\mathrm{pH} 6.8$ and 6.5 are indicated by ${ }^{*} P<0.05,{ }^{* *} P<0.01$. Western blot analysis of VEGF (c) and PEDF (d) protein was normalized by the $\beta$-actin protein levels. Representative blots are shown.

thus possible that the diverse results are obtained from the different approaches.

Although acidosis often follows the onset of hypoxia, study has shown that hypoxia and acidosis can independently upregulate VEGF transcription in brain tumours. ${ }^{10}$ We also revealed in the experiment that the increased production of VEGF induced by retinal acidification is without hypoxia. The thickness of tissue slice in organ culture with air-medium interface is required to be $<400 \mathrm{~mm} \cdot{ }^{18-20}$ It is reported that the thickness of adult SD retina is about $170 \mathrm{~mm},{ }^{21}$ which meets the requirement for organ culture, let alone the neonatal retina. When the neonatal retinas were flattened onto the semiporous membrane of Millicell-CM culture insert and remained at the air-medium interface, they obtained oxygen from above and medium from below to maintain the architecture, which was shown by the intact histology of the retinal explants ( $\mathrm{pH} 7.2$ or 6.8). The swelling and vacuolation of cells in the inner nuclear layer of the retinas of $\mathrm{pH} 6.5$ may be caused by tissue acidification, not because of the organ culture method.

It is widely accepted that hypoxic induction of VEGF is through activation of hypoxia-inducible factor-1.

However, the increased VEGF production by acidosis was reported to result from the activation of nuclear factor- $\kappa \mathrm{B}$ and activator protein- $1,{ }_{1,22}^{11,22}$ which bind to the VEGF promoter. This indicates that acidosis may play a separate role in the pathogenesis of diabetic retinopathy. 
Although hypoxia may develop in the early diabetic retinopathy, ${ }^{23}$ the extraordinarily high rate of glycolysis in the diabetic retina and the sequent accumulation of lactic acid and $\mathrm{H}^{+}$may predominantly contribute to the acidic condition independent of hypoxia. ${ }^{24}$ Consequently, the combined effects on the production of VEGF in these two ways may result in the increased vascular permeability and make the diabetic retina more susceptible to retinal neovascularization.

Acidosis can result in oxidative stress by generation of reactive oxygen species (ROS). Studies have shown that increased ROS could upregulate VEGF in retina and macrophages. ${ }^{25,26}$ In this study, after retinas were incubated with antioxidants, the increased VEGF by mild acidification was completely inhibited; however, that produced by severe acidification, although was reduced to a great extent, was still higher than the normal. This reveals that, besides through oxidative stress, the mechanisms of increased production of VEGF by retinal acidification may include other factors, which is dependent on the severity of acidification. On the other hand, because we did not measure the production of ROS between each group, the still increased VEGF may be caused by more ROS production induced by severe acidification than that by mild acidification, which may not be removed completely by antioxidants.

VEGF and PEDF are both modulated by hypoxia. In contrast to VEGF, hypoxia decreases PEDF expression. PEDF loss was detected in the neovascularized ocular diseases, for example diabetic retinopathy and agerelated macular degeneration. ${ }^{27}$ In this study, retinal acidification could increase production of PEDF mRNA and protein. When antioxidants were added and ROS was removed, PEDF was further increased. This means that the increased PEDF by acidification was not induced by oxidative stress; on the contrary, oxidative stress may inhibit PEDF expression in acidic condition. The mechanisms of induced PEDF by retinal acidification are unknown or may be protective to counteract the effects of increased VEGF.

It is well known that most ischemic retinal neovascularization models closely resemble ROP and are present in mice, but not in rats. Some ascribed this to the stable regulation of PEDF in hyperoxia-treated SD rats. ${ }^{28}$ In addition, experimental diabetic rats showed a loss of pericytes and thickening of the basement membrane of the retinal vessels, similar to the early morphological changes in human diabetic retinopathy, but never develop proliferative retinopathy. Recently, upregulated PEDF was reported in the spontaneously diabetic Torii rats, which was supposed to contribute to the scarcity of the retinal neovascularization. ${ }^{29}$ This study found that retinal acidification could increase the production of PEDF in SD rats, which may help to produce the low incidence of retinal neovascularization in SD rats. It is not identified whether the increased PEDF is determined by the characteristic species. Similar retinal structure and vascular network between rat and human make rat suitable to experiments for human retinal diseases. However, because of the difference between organ culture and in vivo experiment, results from this study are of limited usefulness to human retinal diseases. Despite increased VEGF and decreased PEDF found in the proliferative tissues of patients with hypoxic retinal diseases, the effects of retinal acidosis per se on the human tissues need further investigation.

\section{Acknowledgements}

This work was supported by grant from Shanghai fundus diseases key laboratory.

\section{References}

1 Padnick-Silver L, Linsenmeier RA. Effect of hypoxemia and hyperglycemia on $\mathrm{pH}$ in the intact cat retina. Arch Ophthalmol 2005; 123: 1684-1690.

2 Van den Enden MK, Nyengaard JR, Ostrow E, Burgan JH, Williamson JR. Elevated glucose levels increase retinal glycolysis and sorbitol pathway metabolism. Implications for diabetic retinopathy. Invest Ophthalmol Vis Sci 1995; 36 1675-1685.

3 Birol G, Budzynski E, Wangsa-Wirawan ND, Linsenmeier RA. Retinal arterial occlusion leads to acidosis in the cat. Exp Eye Res 2005; 80: 527-533.

4 Lu DW, Chang CJ, Wu JN. The changes of vitreous $\mathrm{pH}$ values in an acute glaucoma rabbit model. J Ocul Pharmacol Ther 2001; 17: 343-350.

5 Budzynski E, Wangsa-Wirawan N, Padnick-Silver L, Hatchell D, Linsenmeier R. Intraretinal pH in diabetic cats. Curr Eye Res 2005; 30: 229-240.

6 Gatenby RA, Gawlinski ET, Gmitro AF, Kaylor B, Gillies RJ. Acid-mediated tumor invasion: a multidisciplinary study. Cancer Res 2006; 66: 5216-5223.

7 Zhang S, Leske DA, Lanier WL, Berkowitz BA, Holmes JM. Preretinal neovascularization associated with acetazolamide-induced systemic acidosis in the neonatal rat. Invest Ophthalmol Vis Sci 2001; 42: 1066-1071.

8 Holmes JM, Zhang S, Leske DA, Lanier WL. Metabolic acidosis-induced retinopathy in the neonatal rat. Invest Ophthalmol Vis Sci 1999; 40: 804-809.

9 Leske DA, Wu J, Mookadam M, Chen Y, Fautsch MP, Holmes JM et al. The relationship of retinal VEGF and retinal IGF-1 mRNA with neovascularization in an acidosisinduced model of retinopathy of prematurity. Curr Eye Res 2006; 31: 163-169.

10 Fukumura D, Xu L, Chen Y, Gohongi T, Seed B, Jain RK. Hypoxia and acidosis independently up-regulate vascular endothelial growth factor transcription in brain tumors in vivo. Cancer Res 2001; 61: 6020-6024.

11 Shi Q, Le X, Wang B, Abbruzzese JL, Xiong Q, He Y et al. Regulation of vascular endothelial growth factor expression by acidosis in human cancer cells. Oncogene 2001; 20: 3751-3756. 
12 D'Arcangelo D, Facchiano F, Barlucchi LM, Melillo G, Illi B, Testolin $\mathrm{L}$ et al. Acidosis inhibits endothelial cell apoptosis and function and induces basic fibroblast growth factor and vascular endothelial growth factor expression. Circ Res 2000; 86: 312-318.

13 Brooks SE, Gu X, Kaufmann PM, Marcus DM, Caldwell RB. Modulation of VEGF production by $\mathrm{pH}$ and glucose in retinal Muller cells. Curr Eye Res 1998; 17: 875-882.

14 Spector JA, Mehrara BJ, Greenwald JA, Saadeh PB, Steinbrech DS, Bouletreau PJ et al. Osteoblast expression of vascular endothelial growth factor is modulated by the extracellular microenvironment. Am J Physiol Cell Physiol 2001; 280: C72-C80.

15 Padnick-Silver L, Linsenmeier RA. Quantification of in vivo anaerobic metabolism in the normal cat retina through intraretinal pH measurements. Vis Neurosci 2002; 19: 793-806.

16 Nedergaard M, Kraig RP, Tanabe J, Pulsinelli WA. Dynamics of interstitial and intracellular $\mathrm{pH}$ in evolving brain infarct. Am J Physiol 1991; 260: R581-R588.

17 Kaur C, Foulds WS, Ling EA. Blood-retinal barrier in hypoxic ischaemic conditions: basic concepts, clinical features and management. Prog Retin Eye Res 2008; 27: 622-647.

18 Neumann J, Gunzer M, Gutzeit HO, Ullrich O, Reymann KG, Dinkel K. Microglia provide neuroprotection after ischemia. FASEB J 2006; 20: 714-716.

19 Engel D, Pahner I, Schulze K, Frahm C, Jarry H, AhnertHilger $\mathrm{G}$ et al. Plasticity of rat central inhibitory synapses through GABA metabolism. J Physiol 2001; 535: 473-482.

20 Arima H, House SB, Gainer H, Aguilera G. Neuronal activity is required for the circadian rhythm of vasopressin gene transcription in the suprachiasmatic nucleus in vitro. Endocrinology 2002; 143: 4165-4171.

21 Cheng H, Nair G, Walker TA, Kim MK, Pardue MT, Thulé PM et al. Structural and functional MRI reveals multiple retinal layers. Proc Natl Acad Sci USA 2006; 103: 17525-17530.
22 Xu L, Fukumura D, Jain RK. Acidic extracellular $\mathrm{pH}$ induces vascular endothelial growth factor (VEGF) in human glioblastoma cells via ERK1/2 MAPK signaling pathway: mechanism of low $\mathrm{pH}$-induced VEGF. J Biol Chem 2002; 277: 11368-11374.

23 Linsenmeier RA, Braun RD, McRipley MA, Padnick LB, Ahmed J, Hatchell DL et al. Retinal hypoxia in long-term diabetic cats. Invest Ophthalmol Vis Sci 1998; 39: 1647-1657.

24 Van den Enden MK, Nyengaard JR, Ostrow E, Burgan JH, Williamson JR. Elevated glucose levels increase retinal glycolysis and sorbitol pathway metabolism. Implications for diabetic retinopathy. Invest Ophthalmol Vis Sci 1995; 36: 1675-1685.

25 Kuroki M, Voest EE, Amano S, Beerepoot LV, Takashima S, Tolentino $\mathrm{M}$ et al. Reactive oxygen intermediates increase vascular endothelial growth factor expression in vitro and in vivo. J Clin Invest 1996; 98: 1667-1675.

26 Urata Y, Yamaguchi M, Higashiyama Y, Ihara Y, Goto S, Kuwano $\mathrm{M}$ et al. Reactive oxygen species accelerate production of vascular endothelial growth factor by advanced glycation end products in RAW264.7 mouse macrophages. Free Radic Biol Med 2002; 32: 688-701.

27 Spranger J, Osterhoff M, Reimann M, Möhlig M, Ristow M, Francis MK et al. Loss of the antiangiogenic pigment epithelium-derived factor in patients with angiogenic eye disease. Diabetes 2001; 50: 2641-2645.

28 Gao G, Li Y, Fant J, Crosson CE, Becerra SP, Ma JX. Difference in ischemic regulation of vascular endothelial growth factor and pigment epithelium-derived factor in Brown Norway and Sprague Dawley rats contributing to different susceptibilities to retinal neovascularization. Diabetes 2002; 51: 1218-1225.

29 Matsuoka M, Ogata N, Minamino K, Higuchi A, Matsumura M. High levels of pigment epithelium-derived factor in the retina of a rat model of type 2 diabetes. Exp Eye Res 2006; 82: 172-178. 